\title{
CHINESE CONSUMERS' ONLINE GROUP BUYING BEHAVIOUR MODEL
}

\author{
Matthew Tingchi Liu, University of Macau, Macao \\ James L. Brock, Pacific Lutheran University, USA \\ James Gui Cheng Shi, Macau University of Science and Technology, Macao \\ Christopher Rong Wei Chu, Fudan University, China
}

\begin{abstract}
The research investigates Chinese consumers' online group buying behaviors influential factors and model. Group buying is similar to a cooperative, where informal groups organize and buy directly from a wholesaler. Demand aggregation and volume discounting are the two core elements of group buying (Anand and Aron 2003). Both consumers and suppliers benefit in group buying: consumers benefit by paying less or receiving other benefits, and suppliers benefit by selling multiple items in a single transaction (Chen et al. 2007). In traditional markets, it has often been difficult to form a group of people with the identical demand necessary to create a sufficiently large aggregate demand. Most group buying today relies extensively on the internet, which plays an important role in sharing information, recruiting buyers, providing for convenient online payment, etc. (Kauffman et al. 2010). Thus the internet is a powerful tool for demand aggregation and a great platform to organize group buying (Anand and Aron 2003). Group buying has developed rapidly in recent years in many countries, including China because of its nature (the attraction of a lower price) and due to a changed macro environment (i.e., wider spread of the internet, larger number of internet users, more mature technological development).
\end{abstract}

Many different personal factors or preferences could be categorized in shopping orientation, and different consumer shopping orientations lead to different behaviors. Kauffman et al. (2010) explored sequence-based, time-based and quantity-based incentives, as well as consumers' perceptions of fairness in their participation in online group auctions. Furthermore, online shopping orientation was also studied. Li et al. (2006) sorted out many previous perspectives and proposed three orientations positively associated with online buying behavior: (1) Price orientation; (2) Convenience orientation; and (3) Recreational orientation. Online group buying behavior is similar to online shopping behavior in many aspects, so we follows Li et al.'s (2006) classification. H1: Shopping orientation positively influences consumers'attitude towards group buying.

In online shopping, when consumers' perceived risk is low, their purchase intention is high (Järvenpää and Tractinsky, 1999). Bhatnagar et al. (2000) considered that the risks associated with internet shopping were financial risk and product risk. Miyazaki and Fernandez (2001) also thought that privacy risk and credit card security risk were also associated with online buying behavior. Forsythe and Shi (2003) further summarized that there were four perceived risks when customers buy offerings through the internet: (1) Financial risk; (2) Product risk; (3) Psychological risk; and (4) Time risk. The mentioned paper is a great framework to explain perceived risks in online group buying. H2: Perceived risk negatively influences consumers' attitude towards group buying.

The most unique part of group buying, in comparison to traditional buying behavior, is that in online group buying there must be an initiator, who could be a seller, a mediator, or a buyer, before group buying can be realized. So the variable "trust (by buyers) of the initiator" is necessary instead of merging it into perceived risks (cf. Cheung and Lee 2001); and should be isolated as an independent variable instead of being a mediator. This idea was supported by extensive research focusing on the relationship between e-vendors and online shoppers (e.g., Gefen et al. 2003). Kauffman et al. (2010) listed trust of the initiator as a dependent variable in their study regarding the group buying auction intention model. Chang et al (2005)'s study provided a summary of collected findings of the effect of antecedents of trust and found common variables to present trust: (1) structural assurance; (2) perceived reputation, and (3) website quality. H3: Trust of the initiator positively influences consumers' attitude towards group buying.

The theory of reasoned action (TRA) introduced by Ajzen and Fishbein is widely used to explain the relationship between attitude and behavior. TRA postulates that behavior is controlled by behavioral intention. Also, Järvenpää and Tractinsky (1999) found favorable attitudes towards an internet store will increase the consumer's willingness to purchase from that internet store. H4: Consumers' attitude towards group buying positively influences their intention to join online group buying.

Around 600 valid samples were collected via an online survey in China national wide. Multiple regressions results show that consumers' shopping orientation and trust of the initiator both significantly positively influence their attitudes toward group buying. Consumers' perceived risks (mainly product and psychological risks) also negatively influence attitude marginally without significance. The consumers' attitude positively influences their intention to participate in group buying.

\section{REFERENCE AVALIABLE UPON REQUEST}

